(RESEARCH ARTICLE)

\title{
Extraction, isolation, physicochemical characterization, phytochemical and proximate evaluation of pearl millet (Pennisetum glaucum) starch
}

\author{
Afolayan Michael *, Orijajogun Joyce and Bwai Macham David \\ Chemistry Advanced Research Center, Sheda Science \& Technology Complex (SHESTCO), P.M.B 186, Garki - Abuja, \\ Nigeria.
}

Publication history: Received on 13 October 2020; revised on 28 October 2020; accepted on 30 October 2020

Article DOI: https://doi.org/10.30574/wjarr.2020.8.2.0377

\begin{abstract}
Pearl millet (Pennisetum glaucum) is the most widely grown type of millet. Starch was extracted from its seeds and subjected to physicochemical characterization, proximate analysis and phytochemical screening in order to ascertain its properties and adjudge its suitability for use in various industries. Physicochemical characterization of the starch revealed that it had gelatinization temperature of $79^{\circ} \mathrm{C}$, foam and emulsion capacities of 4 and $20 \%$ respectively, $\mathrm{pH}$ of 6.88 , water holding capacity of $28.345 \mathrm{ml}$, bulk and tapped densities of $0.526 \mathrm{~g} / \mathrm{cm} 3$ and $0.667 \mathrm{~g} / \mathrm{cm} 3 \mathrm{respectively}$, browning temperature of $224.5-265.0{ }^{\circ} \mathrm{C}$ and charring temperature of $270.3-290.0{ }^{\circ} \mathrm{C}$. The starch percentage solubility at $90^{\circ} \mathrm{C}$ was 3.2 with a swelling power of 17.65. Pennisetum glaucum starch was discovered to be made up of 17.66\% amylose and $82.34 \%$ amylopectin. Phytochemical screening of the starch showed the presence of saponins, terpernoids, carbohydrates and resins. Proximate analysis of the starch showed ash content of $0.18 \%$, moisture content of $6.97 \%$, crude lipid content of $5.99 \%$, crude protein content of $3.46 \%$ and carbohydrate content of $83.4 \%$. The various results from the characterization of the starch from Pennisetum glaucum showed that it is a potential source of pharmaceutical / industrial starch as its properties compare favourably with those of starch being used in the pharmaceutical industries.
\end{abstract}

Keywords: Pennisetum glaucum; physicochemical; proximate; starch; phytochemical; Pearl millet.

\section{Introduction}

Starch is one of the most abundant organic chemicals on earth. It is found in the leaves of green plants in the plastids where it is synthesized. It is also synthesized in the amyloplasts of seeds, grains, roots and tubers of most plants where it serves as the chemical storage form of energy [1]. Starch is the only qualitatively important digestible polysaccharide and has been regarded as nutritionally superior to low molecular weight carbohydrate or sugars [2]. Though starch is mainly used as food, it can also be readily converted chemically and biologically into many useful and diverse products such as paper, textiles, adhesive, beverages, confectionaries, pharmaceuticals and plastics [3].

Starch is a natural biodegradable biopolymer which has wide industrial applications. It is one of the most widely used biomaterial in the food, textile, cosmetics, plastics, adhesives, paper and pharmaceutical industries. The diverse industrial usage of starch is based on its availablity at low cost, high calorific value and inherent excellent physicochemical properties [4]. The versatility of starch in industrial applications is clearly defined by its physicochemical properties; therefore, a thorough evaluation of the necessary parameters is important in elucidating its industrial use. The morphology and physicochemical characteristics of starch are typical of its biological origin hence, starch from each plant source will vary somewhat in appearance, composition and properties [1].

\footnotetext{
${ }^{*}$ Corresponding author: Afolayan Michael

Chemistry Advanced Research Center, Sheda Science \& Technology Complex (SHESTCO), P.M.B 186, Garki - Abuja, Nigeria. 
Pearl millet, commonly known as bulrush millet with botanical name Pennisetum glaucum (L.) R. Br. Is a cultivated, small-grain, tropical cereal grass. It is locally called bajra in India, gero in Northern Nigeria (Hausa language), hegni in Niger (Djerma language), sanyo in Mali, dukhon in Sudan (Arabic), and mahangu in Namibia. Pearl millet is quantitatively the most important millet, with world annual production of about 14 million tons (Mt). It is cultivated mainly in the semiarid tropics, almost exclusively by subsistence and small-scale commercial farmers. Pearl millet is one of the most important millet species as it accounts for approximately half the total worldwide production of millets. It is mainly cultivated in India and Africa and is uniquely tolerant of hot and dry conditions [5]. The grain of pearl millet generally has higher fat and hence higher energy, higher protein content and better quality protein than most other cereal grains. It is a "high-energy" cereal that contains carbohydrates, protein and fat; rich in vitamins B and A, high in calcium, iron, and zinc, and also contains potassium, phosphorus, magnesium, zinc, copper, and manganese [6]. It has been almost exclusively a subsistence crop but today is becoming widely used in commercial small-scale food manufacture. Many traditional foods and beverages are produced from pearl millet, including couscous and flatbreads, doughs, porridges, gruels, nonalcoholic beverages, and beers. Recently, iron- and zinc-biofortified pearl millet has been developed for improved nutrition [7].

As a result of the competing demands for starch as food, pharmaceutical and industrial uses coupled with the need to attain self-sufficiency in starch production, there is a need to find other high yield sources different from cassava, maize and potato [8]. Thus, the aim of this research was to isolate and purify starch from Pearl millet (Pennisetum glaucum) seeds. The starch thus obtained was thereafter subjected to physicochemical characterization, phytochemical evaluation and proximate analysis to determine its suitability as a potential biomaterial for industrial application.

\section{Material and methods}

Materials

Pearl millet seeds were obtained from Daffo, Bokkos LGA of Plateau State Nigeria and were identified at Federal college of forestry, Jos, Plateau state as Pennisetum glaucum. Corn starch (BP) and other analytical grade reagents were obtained from Chemistry Advanced Research Centre, Sheda Science and Technology Complex, Abuja, Nigeria.

\subsection{Starch Isolation}

The pearl millet seeds were picked to separate dirts and washed. The separated seeds $(0.95 \mathrm{~kg})$ were washed and soaked in sodium metabisulphite solution $(2 \mathrm{~L} 1 \% \mathrm{w} / \mathrm{v})$ overnight at room temperature $\left(27^{\circ} \mathrm{C}\right)$. Thereafter, the hydrated seeds were removed and wet milled into a slurry using a laboratory blender. The paste was dispersed in a large volume of $1 \%$ sodium metabisulphite solution and filtered several times through a muslin cloth. The suspension was centrifuged at $3500 \mathrm{rpm}$ for 10 mins to facilitate the removal of dirts. The supernatant was carefully decanted and the mucilage scraped off. The process was repeated for three times with the mucilage on the starch scraped continuously until a pure starch was obtained. The resulting starch was dried in the sun and further dried at $60{ }^{\circ} \mathrm{C}$ in a hot air oven, pulverized, weighed and stored in sample bottles until required for analysis.

\subsection{Determination of Physicochemical Properties}

\subsection{Swelling Power}

The method described by Afolayan et al (2014) was used to determine the swelling power with slight modifications [9]. The starch sample $(0.1 \mathrm{~g})$ was weighed into a test tube and $10 \mathrm{ml}$ of distilled water was added. The mixture was heated in a water bath at a temperature of $50^{\circ} \mathrm{C}$ for 30 mins with continuous shaking. In the end, the test tube was centrifuged at $1500 \mathrm{rpm}$ for $20 \mathrm{mins}$ in order to facilitate the removal of the supernatant which was carefully decanted and weight of the starch paste taken. The swelling power was calculated as follows:

Swelling power $=\quad$ Weight of starch paste

Weight of dry starch sample

This was carried out over a temperature range of $50^{\circ} \mathrm{C}-95^{\circ} \mathrm{C}$.

\subsection{Solubility Index}

The method described by Afolayan et al (2014) was also used to determine the solubility index with slight modifications [9]. Starch sample $(0.5 \mathrm{~g})$ was added to $10 \mathrm{ml}$ distilled water in a test tube. This was subjected to heating in a water bath 
with a starting temperature of $50{ }^{\circ} \mathrm{C}$ for $30 \mathrm{mins}$. It was then centrifuged at $1500 \mathrm{rpm}$ for another $30 \mathrm{mins} 5 \mathrm{ml}$ of the supernatant was decanted and dried to constant weight. The solubility was expressed as the percentage (\%) by weight of dissolved starch from heated solution. This was carried out over a temperature range of $50{ }^{\circ} \mathrm{C}-95^{\circ} \mathrm{C}$.

\subsection{Gelatinization Temperature}

This was evaluated using the method of Attama et al, (2003) [10]. The starch sample (1 g) was put in a $20 \mathrm{ml}$ beaker and $10 \mathrm{ml}$ of distilled water was added. The dispersion was heated on a hot plate. The gelatinization temperature was then read with a thermometer suspended in the starch slurry.

\subsection{Foam Capacity}

The method of Omojola et al (2010) was used with slight modifications [4]. Starch sample (1 g) was homogenized in 50 $\mathrm{ml}$ distilled water using a vortex mixer (vortex 2 Genie set at shake 8) for 5 minutes. The homogenate was poured into a $100 \mathrm{ml}$ measuring cylinder and the volume recorded after $30 \mathrm{~s}$. The foam capacity was expressed as the percent increase in volume.

\subsection{Emulsion Capacity}

Sample ( $1 \mathrm{~g}$ ) was dispersed in $5 \mathrm{ml}$ distilled water using a vortex mixer for 30 seconds. After complete dispersion, $5 \mathrm{ml}$ vegetable oil (groundnut oil) was added gradually and the mixing continued for another 30 s. The suspension was centrifuged at $1600 \mathrm{rpm}$ for 5 mins. The volume of oil separated from the sample was read directly from the tube. Emulsion capacity is the amount of oil emulsified and held per gram of sample.

\subsection{Browning and Charring Temperature}

The method of Builders et al (2001) was used with slight modifications [11]. Some of the starch sample was put into a capillary tube, the browning and charring temperatures were determined using a melting point apparatus with model Electrothermal 9100.

\section{9. $\mathrm{Ph}$}

A $20 \% \mathrm{w} / \mathrm{v}$ dispersion of the sample was shaken in water for 5 minutes and the $\mathrm{pH}$ was determined using a pH meter.

\subsection{Water Holding Capacity}

The method described by Omojola et al (2010) was used to determine the water holding capacity [4]. The starch sample $(5 \% \mathrm{w} / \mathrm{v})$ was dispersed in a pre-weighed centrifuge tube. The tube was agitated in a vortex mixer for 2 min. The supernatant was then discarded and the weight of the tube and hydrated sample taken. The weight was calculated and expressed as the weight of water bound by $100 \mathrm{~g}$ dry starch.

\subsection{Bulk and Tapped Density}

The bulk density of the starch was determined using the method described by Narayana and Narasinga Rao (1984) with slight modifications [12]. Starch powder $(50 \mathrm{~g})$ was poured into a $250 \mathrm{~cm}^{3}$ calibrated measuring cylinder by means of a short - stemmed glass funnel. The volume occupied by the starch was noted to determine the bulk density.

Bulk density $\left(\mathrm{g} / \mathrm{cm}^{3}\right)=\quad$ Weight of sample

Volume occupied

For the tapped density determination, the cylinder was tapped continuously using a ruler until a constant volume was obtained.

\subsection{Amylose and Amylopectin Content}

Starch sample $(0.1 \mathrm{~g})$ and standard were weighed into separate test tubes. To these test tubes, $1 \mathrm{~cm}^{3}$ of $95 \%$ ethanol and $9 \mathrm{~cm}^{3} 1 \mathrm{~mol} \mathrm{dm}^{-3} \mathrm{NaOH}$ were carefully added. The test tubes were covered with foil paper and mixed thoroughly. The samples were heated for 10 mins in a boiling water bath to gelatinize the starch and cooled very well. The suspensions were diluted 10 times. An aliquot of $0.5 \mathrm{~cm}^{3}$ of the extract was used for analysis where $0.1 \mathrm{~cm}^{3}$ of acetic acid solution was added, followed by the addition of $0.2 \mathrm{~cm}^{3}$ of iodine solution. This was made up to $10 \mathrm{~cm}^{3}$ with $9.2 \mathrm{~cm}^{3}$ of distilled water. The solution was left for 20 mins for colour development, vortexed and read at $620 \mathrm{~nm}$ [13]. 
$\%$ Amylose content $=$

\% Amylose of standard X Absorbance of sample

Absorbance of standard

\subsection{Proximate Analysis}

Moisture, crude protein, crude lipid, ash and carbohydrates was determined according to AOAC (1990) [14]. All the Samples analyzed were done in triplicates.

\subsection{Phytochemical Screening}

Preliminary phytochemical screening of the starch extracted was done according to the procedures described by Sofowora (1993) [15].

\section{Results and discussion}

The starch obtained was found to be a brilliant white, crystalline, non- hygroscopic powder with no smell and a yield of about $32 \%$. The yield is considered to be very appreciable especially when compared with starches from other sources such as cassava and corn. Table 1 shows the results of the physicochemical properties and proximate analysis of pearl millet starch. The swelling profile and solubility profile are shown in Figures 1 and 2 respectively. The phytochemical result of finger millet starch showed the presence of saponins, terpernoids, carbohydrates and resins.

Table 1 Physicochemical Properties \& Proximate Analysis of Pearl Millet Starch

\begin{tabular}{|l|l|}
\hline PARAMETER & VALUE \\
\hline Gelatinization temperature & $79{ }^{\circ} \mathrm{C}$ \\
\hline Foam capacity & $4 \%$ \\
\hline Browning temperature & $224.5-265.0^{\circ} \mathrm{C}$ \\
\hline Charring temperature & $270.3-290.0^{\circ} \mathrm{C}$ \\
\hline $\mathrm{pH}$ & 6.88 \\
\hline Water holding capacity & $28.345 \mathrm{ml}$ \\
\hline Bulk density & $0.526 \mathrm{~g} / \mathrm{cm}^{3}$ \\
\hline Tapped density & $0.667 \mathrm{~g} / \mathrm{cm}^{3}$ \\
\hline Emulsion capacity & $20 \%$ \\
\hline Ash content & $0.18 \%$ \\
\hline Moisture content & $6.97 \%$ \\
\hline Crude lipid & $5.99 \%$ \\
\hline Crude protein & $3.46 \%$ \\
\hline Carbohydrate & $83.4 \%$ \\
\hline Amylose content & $17.66 \%$ \\
\hline Amylopectin content & $82.34 \% \mathbf{7 9}^{\circ} \mathbf{C}$ \\
\hline
\end{tabular}




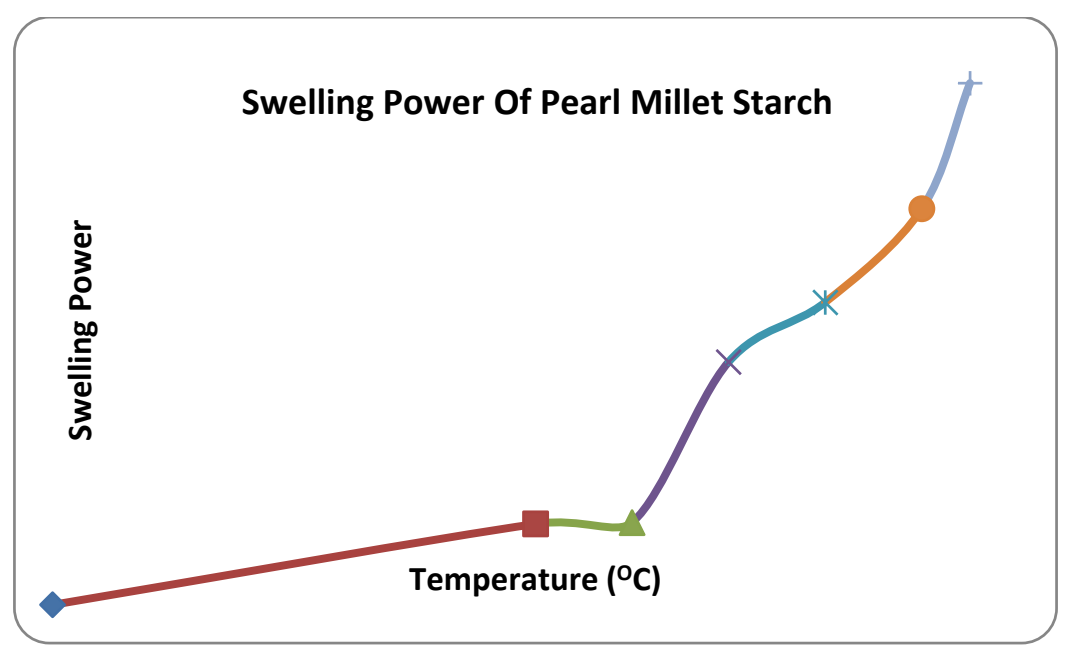

Figure 1 Swelling Power of Pearl Millet Starch

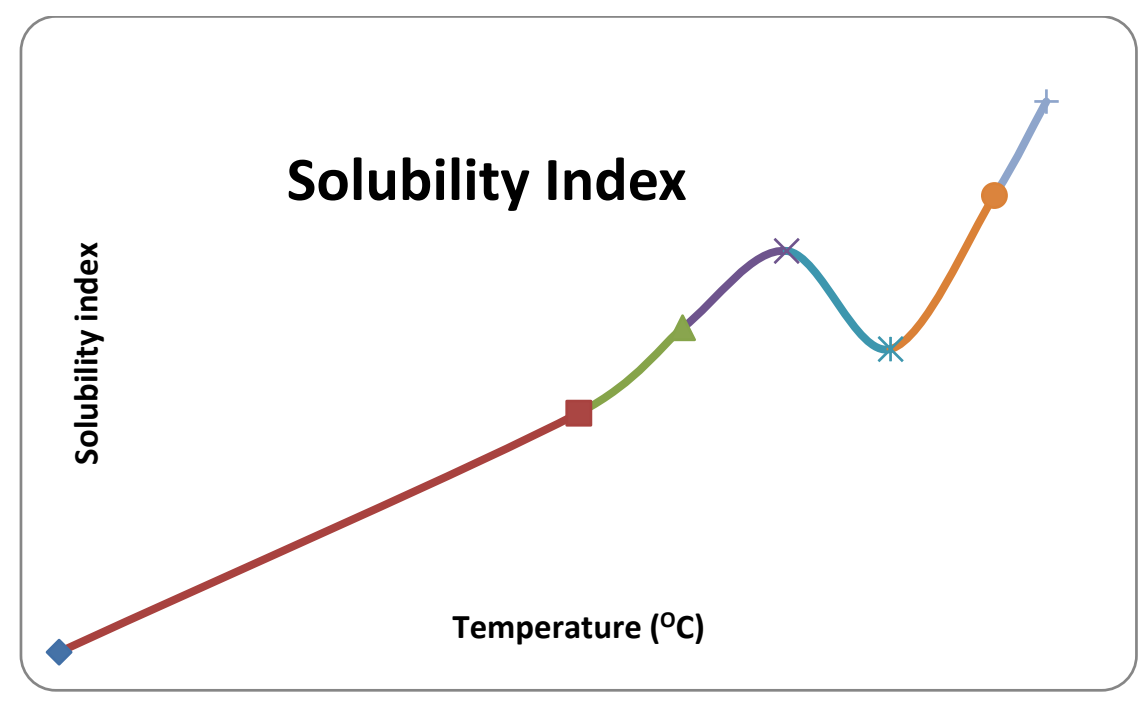

Figure 2 Solubility Index of Pearl Millet Starch

\subsection{Chemical Composition}

Starch isolated from seeds of Pennisetum glaucum was brilliant white, crystalline and non - hygroscopic which is characteristic of pure starch. It also had no smell and had a yield of $32 \%$ which is quite high. It had a gelatinization temperature of $79^{\circ} \mathrm{C}$ which falls within the range of gelatinization temperatures commonly observed for starches. The foam capacity of $4 \%$ and emulsion capacity of $20 \%$ are also as been reported generally for starches. ${ }^{[1]}$ Browning and charring temperatures of starches indicates the temperature to which it can be heated without browning and charring. For pearl millet starch, its browning temperature is quite lower than that reported for maize starch, tiger nut starch and others but can still find application in industries that use starch at very high temperatures while the charring temperature is very much comparable with other starches $[16,17]$. The water absorption capacity of $28.345 \mathrm{ml}$ in 100 $\mathrm{g}$ of sample is very low when compared with earlier results reported for ginger, tiger nut, icacina trichantha, anchomanes difformis and maize starch [18]. The variation in water absorption capacity could be due to different proportion of crystalline and amorphous regions within the granule. This could have an effect on the swelling capacity of the starch also. The bulk and tapped densities are in conformity with the findings of Shihii et al as reported and falls within the range indicated for maize starch [19]. This shows that the starch can be compressed well. Proximate analysis of the starch indicates that its contents are very much comparable with that of cassava, maize and other starches and within the range earlier reported [20]. The high carbohydrate content translates to the high starch yield gotten. The phytochemical screening of pearl millet starch showed that it contained saponins, carbohydrates, terpenoids and resins. The presence of saponins translates to the appreciable foam capacity recorded. The starch was also observed to have quite high amylose content which may not make it a good choice food for diabetics and other health conscious individuals [3]. 


\subsection{Swelling and Solubility}

The swelling and solubility profiles of pearl millet starch over a temperature range of $50-95^{\circ} \mathrm{C}$ are illustrated in Figures 1 and 2. The profiles show a general trend of increase with increase in temperature for the starch although a slightly two - stage swelling pattern can be observed. This is an indication of the water absorption characteristic of the granules during heating. The swelling curve for the starch demonstrated temperature relaxation between $50-60{ }^{\circ} \mathrm{C}$ and also a little at $90^{\circ} \mathrm{C}$ just like it was reported for several other starch [4]. There is first, a slight decrease from $50-60^{\circ} \mathrm{C}$ followed by an increase up till $80^{\circ} \mathrm{C}$ then a slight level off and then another rapid increase from $90{ }^{\circ} \mathrm{C}$. This pattern has been attributed to two sets of internal bonding forces that relax at different temperatures [17]. The swelling power is quite appreciable; higher than tiger nut, ginger and anchomanes starches but lower than maize starch. Increase in swelling power is indicative of suitability of a starch being used as a disintegrant in the pharmaceutical industry [21], hence pearl millet starch can be effectively used as a disintegrant in the formulation of tablets. The solubility profile for the starch shows an initial decrease from $50-70^{\circ} \mathrm{C}$ and thereafter an increase in solubility with temperature rise.

\section{Conclusion}

Pennisetum glaucum starch has been extracted and some of its physicochemical properties analyzed. These properties compare favourably with other starches as gotten from literature. The study has therefore shown that Pennisetum glaucum is a good source of starch and is therefore a potential biomaterial for industrial use especially if its physicochemical properties are improved upon to meet specific industrial grade. This will help to reduce the burden on starch from other well-known sources such as corn, potato and cassava and make starch available at low cost.

\section{Compliance with ethical standards}

\section{Acknowledgments}

The authors are grateful to Mr Adebisi Fagbohun (SHESTCO, Abuja, Nigeria) for assisting with UV spectroscopy.

\section{Disclosure of conflict of interest}

The authors declare that they have no conflict of interest.

\section{References}

[1] Afolayan MO, Omojola MO, Onwualu AP, Thomas SA. Further physicochemical characterization of Anchomanes difformis starch. Agric Biol J of N America, 2012; 3(1):31 - 8.

[2] Ogungbenle HN. Effect of chemical modification on starch of some legume flours. Pakistan J of Nut, 2007; 6(2):167 -71 .

[3] Agbo IU, Odo GE. The effect of hypochlorite oxidation and acetylation on some of the physicochemical properties of icacina trichantha starch. Bio - Res, 2010; 8(1):593 - 7.

[4] Omojola MO, Akinkunmi YO, Olufunsho KO, Egharevba HO, Martins EO. Isolation and physico-chemical characterization of cola starch. African J food, agric, nut dev, 2010; 10(7):2884 - 900.

[5] Taylor JRN. Millet: Pearl. Res module food sci, 2016; https://doi.org/10.1016/B978-0-08-100596-5.00011-1

[6] Santosh KP, Hari DU, Sangam LD, Kothapally NR. Pearl millet. Genetic and genomic resources for grain cereals improvement, 2016; Pp 253 - 89.

[7] Black JL. Animal feed, Encyclopedia of grain science, 2004; Pp 11 - 20.

[8] Gebre - Mariam T, Schmidt PC. Isolation and physicochemical properties of Endset starch. Starch / Starke, 1996; 48(6):208 - 14.

[9] Afolayan MO, Adama KK, Oberafo A, Omojola M, Thomas S. Isolation and Characterization Studies of Ginger (Zingiber officinale) Root Starch as a Potential Industrial Biomaterial. Am J Materials Sci, 2014; 4(2):97 - 102.

[10] Attama AA, Nnamani PO, Mbonu IK, Adiku MU. Effect of hypochlorite oxidation on the physicochemical properties of gladiolus starch. J Pharm Allied Sci, 2003; 1(1):28 - 35. 
[11] Builders PE, Emeje M, Kunle 00. Some physico - chemical properties of cyperus starch - A potential pharmaceutical excipient. J Pharm Allied Sci, 2001; 2(1):138 - 44.

[12] Narayana, Narasinga Rao MS. Effect of partial hydrolysis on winged Bern (Psophocarpus tetragonolobus) flour. J food Sci, 1984; 49:944 - 9.

[13] Juliano BO. Simplified assay for milled rice amylose. Cereal Sci today, 1971; 16:334 - 40.

[14] AOAC. Official methods of Analysis. 15th Ed, Association of official analytical chemists. Washington D.C. 1990; Pp:808, 831 - 35.

[15] Sofowora A. Medicinal plants and traditional medicine in Africa. Spectrum books, Ibadan. 1993; Pp 150.

[16] Adama KK, Afolayan MO, Oberafo AA, Thomas S. Isolation and Physicochemical Characterization of Tigernut (Cyperus esculentus) Starch as a Potential Industrial Biomaterial. Int J Materials Sci Appl, 2014; 3(2):37 - 41.

[17] Fagbohun A, Afolayan M, Ikokoh P, Olajide O, Adebiyi A, Fatokun O, Ayesanmi A, Orishadipe A. Isolation and characterization studies of moringa oleifera root starch as a potential pharmaceutical and industrial biomaterial. Int J Chem Appl, 2013; 5(2):117 - 26.

[18] Omojola MO, Orishadipe AT, Afolayan MO, Adebiyi AB. Preparation and physicochemical characterization of Icacina starch citrate - a potential pharmaceutical / industrial starch. Agric Biol J N Ame, 2012; 3(1):11 - 6.

[19] Shiihii SU, Musa H, Bhatia PG Martins E. Nig J Pharm Sci, 2011; 10(1):91-102.

[20] Adejumo AL, Aderibigbe AF, Layokun SK. Cassava starch: production, physicochemical properties and hydrolysation - a review. Adv Food Energy Security, 2011; 2:8 - 17.

[21] Chowdary KPR, Enturi V. Preparation, characterization and evaluation of starch citrate- a new modified starch as a disintegrant in tablet formulations. Int J Pharm Res Dev, 2011; 12(2):9 - 17. 